\title{
Study on Patent Mapping of Harmonic Drive Technology
}

\author{
Zhilan Chen $^{1, a^{*}}$ and Wei Chen ${ }^{1, b}$ \\ ${ }^{1}$ College of Mechanical and Electrical Engineering Shanghai Jianqiao University. Shanghai, China \\ a12077@gench.edu.cn,842160486@qq.com
}

Keywords: Harmonic drive; Patent map; Patent analyses

\begin{abstract}
Using IPC classi mfication method (International Patent Classification) and data collection, patent information hiding in the technological field of the Harmonic Drive is mined. The corresponding patent map is drawn, issues related to research Harmonic Drive technology in the global scope of the patent layout, key technology and research focus are studied. The technology industry development trend, key technology areas and competition mechanisms are analyzed. Patent the main patent applicant applied only involves 5 main technical fields. The domestic research institutions need to increase the technology covered so as to be able to cope the birth of new technology and to draw development present situation and future development trend in the field of technology.
\end{abstract}

\section{Introduction}

Harmonic gear transmission technology is a new transmission technology born of the development of space technology in the 1950s of last century. Harmonic Drive is mainly composed of three basic components: fixed rigid internal gear, flexible gear, and wave generator make the radial deformation. Because of the simple structure, large transmission ratio, high transmission efficiency and other advantages, in recent decades, Harmonic Drive is widely used in Space technology, Radar communication, Energy field, Machine tool, Instruments and Apparatuses, Robots, Automobile, Shipbuilding, Spin, Metallurgy, Conventional Weapons, Precision optical equipment, Printing and packaging machinery and Medical apparatus and instruments and other fields [1-3].

As a useful tool to reveal the patent information figuratively, Patent Map is easy to understand, powerful, is of great significance to the development of technology, and has a great guiding significance to the leading technology and technological development of the enterprise [4].

In this paper, we scared 5169 domestic and foreign harmonic drive patent data published from 1957 to 2016. Draw the patent map of harmonic drive analyzed it. Discussed the development status of the global harmonic drive, we also put forward some suggestions on the development direction of the harmonic drive in China.

\section{Global Patent Analysis of Harmonic Drive}

\section{Annual Trend of Harmonic Drive}

The world's first harmonic drive patent appeared in 1957 which was filed by C.W. Musser. In 1960, it was first use successfully by USM Co. and later by Hasegawa Gear Works.

As can be seen from the data in Fig. 1, from harmonic drive technology was born to 1970, the number of global patent applications is very small. In 1970, Hasegawa Gear Works Ltd. became Harmonic Drive Systems Inc. located in Japan [5]. In 1987, Harmonic Drive AG and HD Systems Inc. established. With the wide spread of harmonic drive technology, the number of patents in the period from 1970s to the end of the twentieth Century began to grow rapidly. And the number of patents in 1990s grew significantly.

Since the beginning of twenty-first Century, with the development of this technology and the research of harmonic drive technology in China, the global harmonic drive patent applications grew 
rapidly. In 2013, the total number of patent applications of harmonic drive reached a peak, and then from 2014 to 2016 there was a significant downward trend.

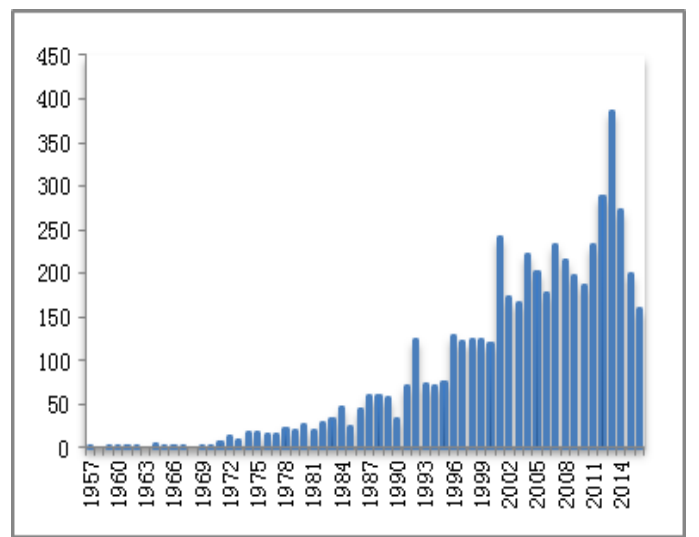

Figure 1.Annual trend of global patent application of harmonic drive

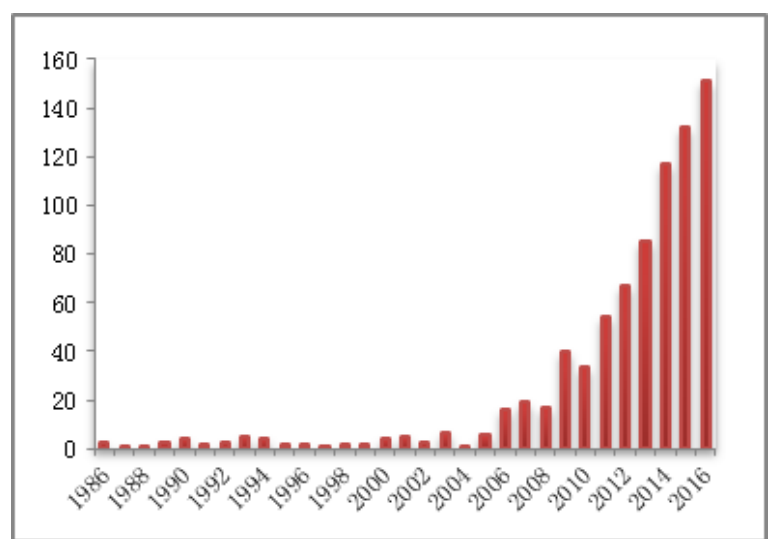

Figure 2.Annual trend of Chinese patent application of harmonic drive

China established the harmonic drive laboratory in 1983.In 1984, "Harmonic Drive Standard products" passed appraisal in Beijing. In 1993, China formulated the GB/T 14118-93 harmonic drive standard, and has got great success in theoretical research, trial production and application which helped China became one of the countries who master the technology [5].

The data in Fig. 2 shows that China's first Harmonic Drive patent applications appeared in 1986. From 1980s to the beginning of the year of twenty-first Century, on the one hand, due to the limited capacity of the research and development of harmonic drive. On the other hand, Chinese scientific research institutions and related enterprises patent protection consciousness is weak. The number of harmonic drive patents was small. After 2000, with the support of relevant national policies and major projects, the patent application of harmonic drive in China has increased rapidly, the number of patent applications of harmonic drive reached peak value in 2016.

\section{Global Harmonic Drive Patent Distribution}

As the data shown in Fig. 3, in all of the global harmonic drive patents, the number of patent applications in Japan reached 923, ranked in the first. The rest of the world's top 5 countries are China, the United States, Germany and South Korea, and their patent applications are 793, 628, 348 and 203.

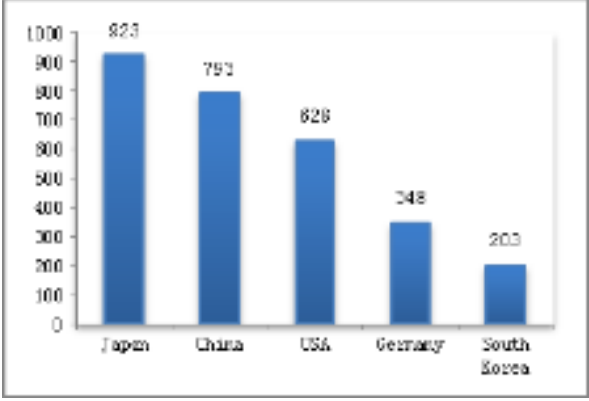

Figure 3.Harmonic drive global top five patent applications

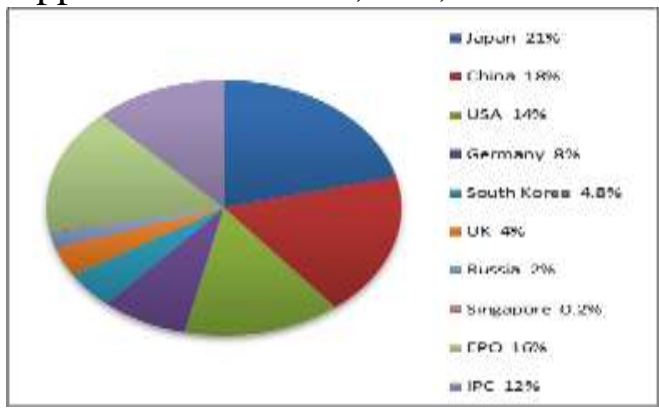

Figure 4.Global distribution of harmonic drive patents

It is not difficult to find the data by observing Fig. 4, Global harmonic drive patents are from 8 countries and 2 intellectual property organizations. Japan ranked first and accounted for more than 21\%; China and the United States ranked second and third, respectively, accounting for 18\% and $14 \%$. Germany ranked fourth and accounted for $8 \%$. South Korea ranked fifth and accounted for $4.8 \%$. Britain accounted for $4 \%$, Russia accounted for $2 \%$ who ranked sixth and seventh. Singapore accounted for 
$0.2 \%$ and ranked eighth. In addition, the European Patent Office patent applications accounted for 16\% which exceed the United States. There are also 12\% patents applied through IPC organizations.

\section{Top 10 patent applications}

As the data shown in Table 1, most of the top ten applicants are enterprise. Among the top 10 applicants for patent applications, U.S. institutions accounted for three, Japanese institutions, German institutions, Chinese institutions accounted for two respectively. The other one are South Korean institutions.

In the harmonic drive related technology patents, from the perspective of patent active stage, most applicants' patent applicant has been maintained for more than 10 years. The active stage of the patent application last for more than 20 years was respectively Harmonic Drive Systems Inc., Harmonic Drive AG, Harmonic Drive L.L.C. and Samick adm CO.LTD. Among them, the earliest start to apply for a patent is Harmonic Drive Systems Inc., which has 40 years of history and the total number of patent applications reached 1037.

Table 1 Harmonic drive global top 10 applicants

\begin{tabular}{lllll}
\hline Sorting & Applicant & Active stage & Country & Number \\
\hline 1 & Harmonic Drive Systems & 40 years $(1976-2015)$ & Japan & 1037 \\
\hline 2 & Harmonic Drive AG & 25 years $(1992-2016)$ & Germany & 712 \\
\hline 3 & Harmonic Drive L.L.C. & 24 years $(1992-2015)$ & USA & 261 \\
\hline 4 & Oechsler & 14 years $(2000-2013)$ & Germany & 115 \\
\hline 5 & Samick adm CO.,LTD. & 24 years $(1992-2014)$ & Korea & 83 \\
\hline 6 & Delphi & 12 years $(2004-2015)$ & USA & 61 \\
\hline 7 & Toyota & 18 years $(1991-2008)$ & Japan & 57 \\
\hline 8 & HIT & 22 years $(1994-2015)$ & China & 44 \\
\hline 9 & Teijin Seiki (Boston) & 11 years $(1990-2000)$ & USA & 37 \\
\hline 10 & Zhejiang Laifu & 3 years $(2014-2016)$ & China & 36 \\
\hline
\end{tabular}

As shown in Table 2, in accordance with international patent classification, the type of technology related to the patent application of harmonic drive is mainly concentrated in Transmission, Manipulator, Electric machinery, Nonspecific measurement, Shaft or bearing and other aspects.

Table 2 Classification of main technical types of global harmonic drives

\begin{tabular}{llll}
\hline Sorting & Applicant & Interpretation & Number \\
\hline 1 & F16H & Transmission & 1587 \\
\hline 2 & B25J & Manipulator & 376 \\
\hline 3 & H02K & Electric machinery & 309 \\
\hline 4 & G01D & $\begin{array}{l}\text { A measurement that is not specific to a } \\
\text { particular variable }\end{array}$ & 108 \\
\hline 5 & F16C & Shaft or bearing & 103 \\
\hline 6 & F16D & coupling & 68 \\
\hline 7 & G02B & An optical element, system, or instrument & 66 \\
\hline 8 & G05B & Control or regulation system & 63 \\
\hline 9 & F01L & Cycle operated valve & 57 \\
\hline 10 & B41F & Printing machinery & 57 \\
\hline
\end{tabular}

As the data shown in Fig. 5, transmission is the field pays attention to the development and improvement of harmonic drive itself. In this field, Harmonic Drive Systems company has absolutely 
technological superiority. The number of patent applications from Three Harmonic Drive Systems company and Samick Adm CO.,LTD which Harmonic Drive Systems Inc. hold controlling interest in this field. Manipulator is the fields pay more attention to the use of harmonic drive. In this field, Harmonic Drive AG, Toyota and Harbin Institute of Technology are stronger. Harmonic Drive L.L.C. is stronger in Optical original system. Patent in Circulating valve field are held by Delphi and Toyota.

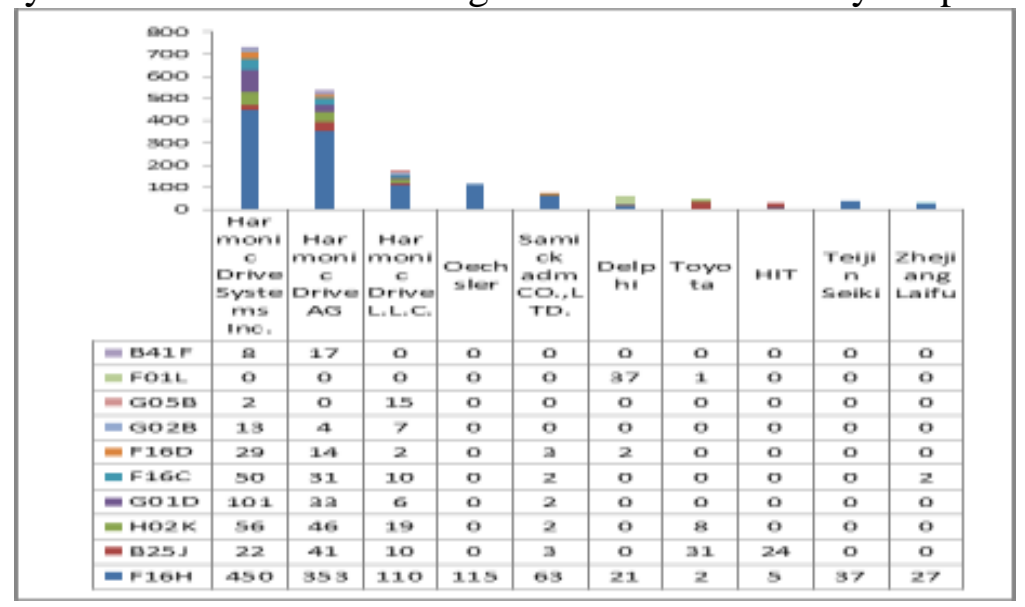

Figure 5.The number of patent applications from world's top 10 applicants in major technical fields

Fig. 6 shows the patent distribution of Chinese institutions in major technical fields. The distribution of domestic technology types mainly concentrated in Transmission and Manipulator fields. The number of the patent applications in these two areas was 208 and 206 which accounted for $61 \%$ of the total number of patent applications in China. In the main technical field, the number of patents in Transmission and Manipulator fields is far more than other fields.

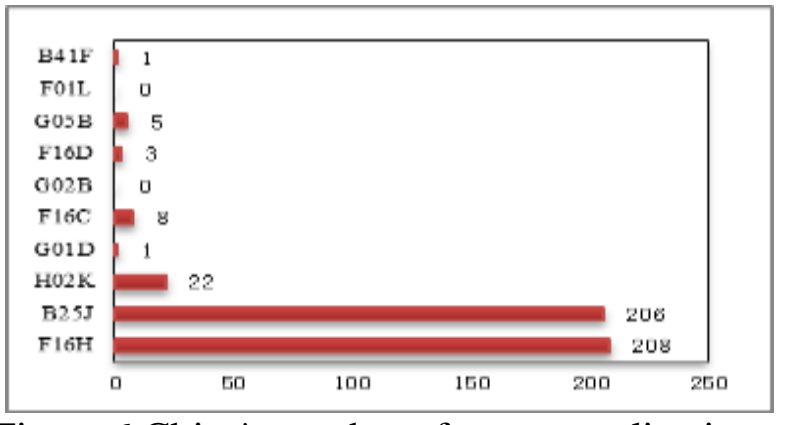

Figure 6.China's number of patent applications in major technical fields

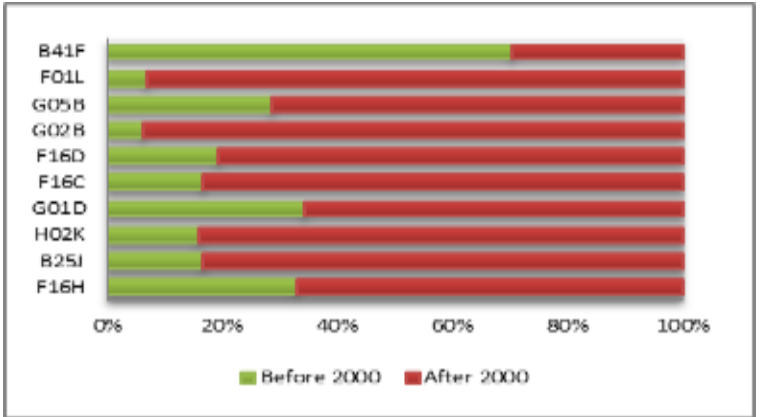

Figure 7.The main technical hotspots changing of harmonic drives

\section{The main technical hotspots changing}

We selected 2000 as the dividing line of the main hot points of the harmonic drive. As can be seen from Fig. 7, the main research direction of harmonic frive before 2000 was Transmission, Nonspecific measurement, Optical original system and other fields. After 2000, the patent in Circulating valve, Optical original system or instrument increased significantly. Other technology hotspots changing directions are Electric machinery, Shaft or bearing, Manipulator, Coupling and other fields. While Printing Machinery has little change over time which is a kind of long term research technology.

\section{Conclusion}

Based on the analysis of the domestic and international patent search, data mining and analysis of the harmonic drive, we have produced a series of harmonic reducer patent management map and patent 
technology map. According to the patent data mining and information analysis of harmonic reducer technology in China and other countries, the following conclusions can be drawn:

- The development of harmonic drive in our country started late. However, with the development of China's R \& D capability, China's patent application in harmonic drive has been ranked second in the world. The main patent applicants of the global harmonic drive have different emphases on the major technical fields. Patent the main patent applicant applied only involves 5 main technical fields. The domestic research institutions need to increase the technology covered so as to be able to cope the birth of new technology.

- Harmonic Drive Systems Inc. still is the leader of the Harmonic Drive industry, who are in a leading position in both the number of the patents and the technical scope of the patents. While China has only 1 company ascend the world's top 10 patent applicants. In addition, the domestic patents are mainly focus on the application of harmonic reducer. While most foreign companies pay more attention to the development and improvement of harmonic drive technology. That indicates that there is a big difference in the field of harmonic drive in recognition between the domestic and foreign research. The state should strengthen the guidance of domestic universities and scientific research institutions in the technical research and development capabilities of harmonic drive and improve the quality of domestic harmonic drive as soon as possible in order to improve the competitiveness of domestic harmonic drive in the international market finally.

- From a technical point of view, Harmonic Drive Systems Inc. has obvious advantage of patent technology in the field of Transmission, Electric machinery, Nonspecific measurement, Shaft or bearing, Coupling, Printing machinery and other fields. Oechsler has more patents in the field of Transmission. Delphi has a great advantage in the field of Circulating valve. Toyota and Harbin Institute of Technology have a great advantage in the field of Manipulator.

\section{Acknowledgments}

The financial support from key course of construction project (SJPKC2016001) and project of construction and research of industrial robot application degree (230001-17-13) by Shanghai Municipal Education Commission is gratefully acknowledged.

\section{References}

[1] Huang Xin, He Wenjie, Fu Yuanxiang. Summary of Precision Speed Reducer of Industrial Robots [J]. Machine Tool \& Hydraulics,2015,43(13) :1-6.

[2] Zhou Hui,Wen Qingping,Zhang Weiwen. Harmonic Drive used in Spacecraft [J]. Vacuum \& Cryogenics,2004,10(4) :187-192.

[3] Wang Jun, Wang Jiaxu, Cheng Meilin, Li Kang. Study on the Reliability of Space Harmonic Reducer [J]. Journal of Mechanical Transmission, 2013, 37(12):1-4.

[4] Changyong Lee, Bokyoung Kang, Juneseuk Shin, Novelty-focused patent mapping for technology opportunity analysis [J]. Technological Forecasting \& Social Change, 2015, (90):355-365.

[5] Wang Changming. Overview of harmonic gear drive [J]. Journal of Mechanical Transmission. 2006,30(4):86-88. 